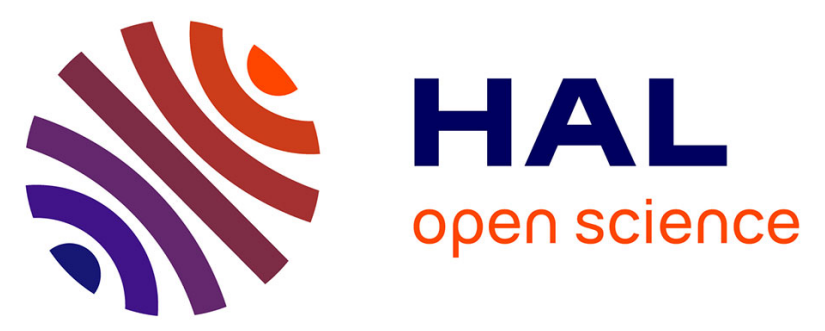

\title{
Treatment of life-threatening emergencies in the workplace: need for collaboration between emergency and occupational health services?
}

Laurent Geraut, Alexis Descatha

\section{- To cite this version:}

Laurent Geraut, Alexis Descatha. Treatment of life-threatening emergencies in the workplace: need for collaboration between emergency and occupational health services?. Resuscitation, 2012, 83 (3), pp.e65-6. 10.1016/j.resuscitation.2011.11.028 . inserm-00720685

\section{HAL Id: inserm-00720685 https://www.hal.inserm.fr/inserm-00720685}

Submitted on 25 Jul 2012

HAL is a multi-disciplinary open access archive for the deposit and dissemination of scientific research documents, whether they are published or not. The documents may come from teaching and research institutions in France or abroad, or from public or private research centers.
L'archive ouverte pluridisciplinaire HAL, est destinée au dépôt et à la diffusion de documents scientifiques de niveau recherche, publiés ou non, émanant des établissements d'enseignement et de recherche français ou étrangers, des laboratoires publics ou privés. 


\section{Life-threatening emergencies management in workplace: needs for collaboration between emergency and occupational health services?}

Laurent Geraut ${ }^{1}$, Alexis Descatha ${ }^{1,2}$

1 UVSQ AP-HP. Occupational health unit - Inserm U1018, Population-Based Epidemiological Cohorts ” Research Platform, F-94807, Villejuif, France

2 AP-HP, SAMU92- SMUR de Garches (EMS of Paris West Suburb), Poincare Teaching Hospital, F-92380 Garches, France

Adress for reprints: Dr. Alexis Descatha, Unité de pathologie professionnelle/ U1018 INSERM/SAMU92, CHU Poincaré, 104 bd Poincaré, 92380 Garches, France

Tel: +33 (1) 471077 54; Fax: +33 (1) 471077 68; email: alexis.descatha@ @rpc.aphp.fr

\section{Contributions.}

Laurent Geraut was involved in the acquisition of the data, analysis and drafted the manuscript.

Alexis Descatha was involved in the conception of the study, interpreted the data, and revising manuscript critically.

Laurent Geraut and Alexis Descatha approved the final version of the manuscript.

Funding. None.

Conflict of interest: None. The authors did not receive any financial or other types of advantages from the involved company.

Acknowledgements: The authors would like to thanks Drs C. Donnay and C. .Gressin. Thes authors would also like to thank all the occupational physicians and nurses on the involved company.

\section{Keywords:}

Workplace; emergency care; prehospital; occupational; evaluation; protocol. 


\begin{abstract}
Introduction. Life-threatening emergencies could occur in different setting including workplace. We aimed to describe life-threatening emergencies and evaluation of implementation of new protocols in a large multisite company.
\end{abstract}

Method. The evaluation included two 6-month period without and with implementation of the new protocols, where each nurse and physician filled out a questionnaire at each emergency occurring for a life-threatening symptom A global evaluation of these protocols was also performed.

Results. In the cumulative one year period, 75 emergency cares were provided, 0.75 case/1000 workers/ months. Chest pain was the main motive of emergency care. In 7 cases (9.3\% confidence interval at 95\%: 3.8-18.3) the situation was considered by the health professional to be really-life-threatening (no death occurred).

No difference between severity and management in the 45 emergencies in period $\mathrm{A}$ and 30 in period B.

Conclusion. Life-threatening emergency is a rare event but that occupational health service, if they existed, should be prepared to many different situations, in a collaboration between Emergency Medical System and Occupational Health Services to improve management of potentially life-threatening situations, and appropriation and integration of the protocol of the specificity of the workplace environment. 
Sir,

Life-threatening emergencies could occur in different setting including workplace. Many large companies are equipped with an occupational health services including nurses and physicians.

Cardiac arrest management is usually well established in these companies, based on international consensus [1]. Since the last decade, international consensus also included other life-threatening emergencies like acute coronary syndrome, tachycardia. However, even though protocols are sometimes established, large variations of practices exist [2].

Fifteen standardized protocols based on symptoms of major life-threatening emergencies were then developed by a group of occupational and emergency physicians (from prehospital care unit). They included all symptoms which required special care to avoid a potential lifethreatening condition, like chest pain, coma, dyspnea, abdominal pain, severe trauma, anaphylaxis... They were implemented experimentally in a large multisite company for evaluation. We aimed to describe life-threatening emergencies and evaluation of implementation of new protocols in this company.

A large industrial company, including over 8000 workers in 15 locations, was chosen to implemented protocols. Inside- occupational health services included 5 physicians and 25 nurses. Protocols were available but were not revised since 2004. The evaluation included a 6month period between 2009 November and Aril 2010 without implementation of the new protocols (A period), and a 6-month period between 2010 November and Aril 2011 with new protocols. Each nurse and physician filled out a questionnaire at each emergency occurring for a life-threatening symptom including type of distress, severity evaluation (life- 
threatening?). A global evaluation of these protocols was performed using numeric scales (0 to 10) on the benefice of the new protocols, and their ergonomic, effectiveness and exhaustiveness.

In the cumulative one year period, 75 emergency cares were provided, 0.75 case/1000 workers/ months. The mean age was 43.9 years $(+/-11.2)$. Chest pain was the main motive of emergency care (Table 1), and managed in $34 \%$ cases by the occupational health physician. In 7 cases $(9.3 \%$ confidence interval at $95 \%: 3.8-18.3)$ the situation was considered by the health professional to be really-life-threatening (no death occurred).

The comparison of the two periods did not show any difference between severity and management in the 45 emergencies in period $\mathrm{A}$ and 30 in period $\mathrm{B}$. Although found effective and exhaustive (mean $8.0+/-1.5)$ and quit ergonomic (6.6+/-1.7), only few occupational health professional answered to the global evaluation $(n=7)$.

Life-threatening emergency is a rare event but that occupational health service, if they existed, should be prepared to many different situations. Nurses should have standard procedures to manage potential life-threatening emergency when occupational health physician is not there. However, no difference was found between the new validate evidence-based protocols and integrated old protocol.

The small statistical power of the study related to number of event and low response rate at the found could partly explain the results. However, the number of events is an expected result, based on cardiac arrest studies: indeed, workplace is one of the least frequent sites of out-of-hospital cardiac arrest, although there very few publications in this area [3-6]. The low response rate is an important limitation, but the turnover during the period in addition of the overactivity reported by the occupational professionals gave a possible explanation. 
This study gave a fair description of emergency care in large companies, especially the importance of chest pain and lipothymia, as previously found on a retrospective study on Emergency Medical Service call coming from workplace [2]. Old protocols were not standardized but adapted to specificities of the company and well known by nurses. However, some elements based on new recommendations were missing. Better learning and training on new protocols are probably were enough developed in the study ( 8 has no or less than 4 hours of training). Then, it emphasized on the mandatory collaboration between Emergency Medical System and Occupational Health Services to improve management of potentially lifethreatening situations, and appropriation and integration of the protocol of the specificity of the workplace environment.

\section{References}

[1] Nolan JP, Soar J, Zideman DA, Biarent D, Bossaert LL, Deakin C et al. European Resuscitation Council Guidelines for Resuscitation 2010 Section 1. Executive summary. Resuscitation 2010; 81:1219-1276.

[2] Descatha A, Templier F, Coninx P, Dolveck F, Cahun-Giraud S, Baer M et al. Description des urgences en milieu de travail urbain justifiant le recours au SAMU/ Centre 15. Arch Mal Prof 2003; 64:478-485.

[3] Engdahl J, Herlitz J. Localization of out-of-hospital cardiac arrest in Goteborg 19942002 and implications for public access defibrillation. Resuscitation 2005; 64:171-175.

[4] Muraoka H, Ohishi Y, Hazui H, Negoro N, Murai M, Kawakami M et al. Location of out-of-hospital cardiac arrests in Takatsuki City: where should automated external defibrillator be placed. Circ J 2006; 70:827-831. 
[5] Descatha A, Frederic M, Devere C, Dolveck F, Goddet S, Baer M et al. Details of the initial management of cardiac arrest occurring in the workplace in a French urban area. Resuscitation 2005; 65:301-307.

[6] Descatha A, Baer M. Automated external defibrillators in the workplace. BMJ 2008; 337:a1816. 
Table 1. Emergency situations and related to protocol, and prevalence (one year) and confidence interval at $95 \% \%\left(\mathrm{CI}_{95 \%}\right)$

\begin{tabular}{|l|l|l||}
\hline & $\mathbf{n}$ & $\mathbf{\%}\left(\mathbf{C I}_{\mathbf{9 5}}\right)$ \\
\hline Chest pain & 20 & $26.7 \%(17.1-38.1)$ \\
\hline Lipothymia & 9 & $12.0 \%(5.6-21.6)$ \\
\hline Acute agitation & 7 & $9.3 \%(3.84-19.3)$ \\
\hline Acute pain (chest/abdominal/head pain excluded ) & 6 & $8.0 \%(3.0-16.6)$ \\
\hline High blood pressure & 6 & $8.0 \%(3.0-16.6)$ \\
\hline Abdominal pain & 6 & $8.0 \%(3.0-16.6)$ \\
\hline Other : renal colic, other bleeding... & 6 & $8.0 \%(3.0-16.6)$ \\
\hline Stroke ? & 5 & $6.7 \%(2.2-14.9)$ \\
\hline Acute trauma & 5 & $6.7 \%(2.2-14.9)$ \\
\hline Anaphylaxis & 2 & $2.7 \%(0.3-9.3)$ \\
\hline Seizure & $\mathbf{7 5}$ & $\mathbf{1 0 0 \%}$ \\
\hline Dyspnea/ Asthma & $2.7 \%(0.3-9.3)$ \\
\hline Total & $1.3 \%(0.03-7.2)$ \\
\hline \hline
\end{tabular}

